\title{
Flow characteristics of Axisymmetric Cavity Rear Wall Divergence Angle in a Scramjet Combustor
}

\author{
Shan M Assis, S. Jeyakumar, K. Jayaraman
}

\begin{abstract}
Non-reacting experimental study was performed on a rear wall angled cavity actuated supersonic flow of Mach 1.5 from a convergent divergent nozzle using a blowdown wind tunnel test setup. Ten different model combinations of double angled rear wall cavities is preferred for the study of improvements in the geometrical design of the combustor. Flow field properties of various cavity geometries were analyzed based on the key parameters like, wall static pressures, stagnation pressure loss to the flow and qualitative mixing of flow using momentum flux distribution. The static pressure is found to decrease inside the combustor with a decrease in the secondary dual rear wall angle below 90 degrees whereas value increases at the rear wall OWING to oscillation and recompression of shear layers inside the cavity region. In addition, the decrement in primary rear wall angle, an enhancement in mixing profile and a reduction in stagnation pressure loss are also observed.
\end{abstract}

Keywords : Cavity divergence angle, scramjet, momentum flux distribution, wall static pressure, pressure loss.

\section{INTRODUCTION}

$S_{\text {cramjet engines have drawn an increasing attention of }}$ researchers worldwide as they are expected to decrease the travel cost immensely for the future aircrafts, space transport and missile technology. Even being the most difficult mode to implement among the combined cycle engines, growing scientific efforts have been focused so far on to the methods of mixing of high speed incoming air with fuel, ignition and anchor the flame within the combustor to sustain combustion of the scramjet mode. This is mainly because of the very short residence time of the fuel inside the scramjet combustor [1]. Flameholding is one of the most significant and very intricate device in the development of a scramjet combustors $[3,6,7]$.

Out of the various flameholding devices put forward by researchers such as strurts, cavities, and ramp injectors; cavity flameholders have reported to have few problems with aerodynamic heating and drag [9]. But, the comprehensive information refraining the performance of these devices in an axisymmetric combustor model is largely unavailable in the

Revised Manuscript Received on December 30, 2019.

* Correspondence Author

Shan M Assis, Mechanical Engineering, Kalasalingam Academy of Research and Education, Tamil Nadu, India. Email: shanmassis@gmail.com

* S. Jeyakumar, Aeronautical Engineering, Kalasalingam Academy of Research and Education, Tamil Nadu-626126, India. Email: sjeyakumar1974@gmail.com

K. Jayaraman, Aerospace Engineering, Indian Institute of Technology Madras, Chennai-600008, India. Email: jayaraman78@gmail.com existing literature. Unsteady shear layers and hence the pressure oscillations generated within the flow field of the scramjet engines is an important parameter to achieve better mixing [8]. The parameters influence the flow over cavity are the flow Mach number, the approaching boundary layer, aspect ratio of the cavity, configuration of the cavity, etc. [2-5].These shear layers reattachments within the wall mounted cavities can be controlled with cavity geometry for better mixing augmentation. It is stated that the characteristics of the shear layer that spreads over the entire cavity regime are determined by the cavity aft ramp angles. It is reported that the aft ramp angles play a major role for estimating the features of the shear layer which spans over the cavity regime. $[13,14]$. Based on the aspect ratios (length to depth), the cavities are generally categorized as open and closed. Cavity possess $\mathrm{L} / \mathrm{D}$ ratio less than 10 is noted as open cavity and the one with $\mathrm{L} / \mathrm{D}$ ratio greater than 10 termed as closed cavity [12]. In order to minimise the effect of localized and ineffective fuel-air mixing associated with the cavities, improvements in the geometrical design of the combustor with the cavities could rectify various significant issues in the development of Scramjet technology.

In this paper, the behaviour of axisymmetric rear wall angle cavities at Mach number 1.5 flow field is investigated. The cavities rear wall is diverged to two succeeding angles. The rear cavity wall configurations allow a combination of three primary and secondary angles to establish nine sets of patterns of cavity. The cavity features are estimated from its static pressure generated over the combustor wall, momentum flux distribution and stagnation pressure loss due to the cavity flow at combustor exit. The rear wall angled cavities results are are contrasted with a rectangular cavity for performance evaluation.

\section{EXPERIMENTAL DETAILS}

The influence of axisymmetric rear wall angled cavity flow experiments is conducted in a supersonic flow facility with blow-down type. The facility has a supersonic nozzle with a Mach 1.5 flow, 3.45 bar operating pressure and atmospheric temperature. A duct with circular cross-section is connected at nozzle exit which acts as the supersonic combustor. The combustor is of $95 \mathrm{~mm}$ in length and $26 \mathrm{~mm}$ in diameter. The layout of the supersonic combustor (test section) is incorporated with a cavity as shown in Figure 1.

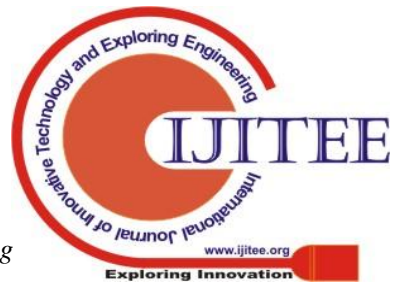


The cavities are positioned from the inlet section at $20 \mathrm{~mm}$ in the combustor. For this investigation, open-type axisymmetric cavities are used. Here, the cavity length and depth are maintained constant but the rear wall angle is varied (Figure 2). In the rear wall of the cavity, two succeeding angles are formed which is inclined towards flow direction, the first inclination denoted as primary $\left(\theta_{1}\right)$ which starts from the base of the cavity and the second inclination mentioned as the secondary $\left(\theta_{2}\right)$ emanated at half from the depth of the cavity. The cavity geometry details are given in Table 1 .

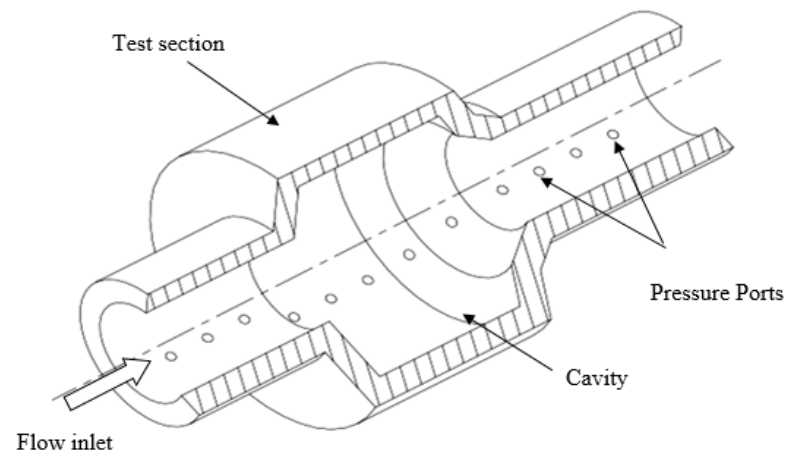

Fig. 1.Schematic view of Supersonic Combustor.

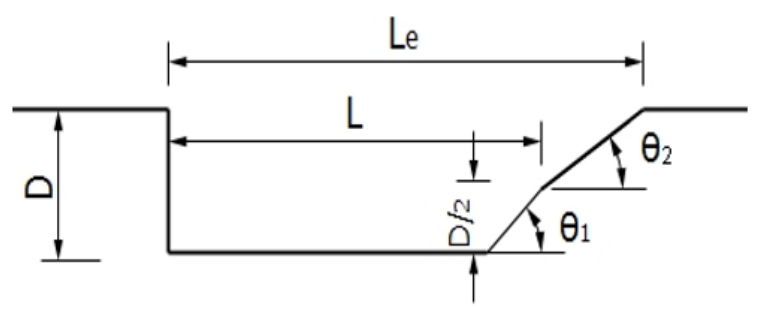

Fig. 2.Schematic diagram of Cavity Layout.

TABLE I. GEOMETRICCAL DETAILS OF CAVITY CONFIGURATION

\begin{tabular}{|l|c|c|c|c|}
\hline Notation & $\begin{array}{c}\text { Cavity } \\
\text { L/D }\end{array}$ & $\begin{array}{c}\text { Effective } \\
\text { Le/D }\end{array}$ & $\begin{array}{c}\text { Primary } \\
\text { angle } \\
\left(\theta_{1}\right)\end{array}$ & $\begin{array}{c}\text { Secondary } \\
\text { angle } \\
\left(\theta_{2}\right)\end{array}$ \\
\hline 90,90 & 4 & 4.0 & 90 & 90 \\
\hline 90,45 & 4 & 4.4 & 90 & 45 \\
\hline 90,30 & 4 & 4.9 & 90 & 30 \\
\hline 90,15 & 4 & 6.0 & 90 & 15 \\
\hline 60,45 & 4.3 & 4.75 & 60 & 45 \\
\hline 60,30 & 4.3 & 5.1 & 60 & 30 \\
\hline 60,15 & 4.3 & 6.0 & 60 & 15 \\
\hline 30,45 & 4.9 & 5.3 & 30 & 45 \\
\hline 30,30 & 4.9 & 5.7 & 30 & 30 \\
\hline 30,15 & 4.9 & 6.65 & 30 & 15 \\
\hline
\end{tabular}

Pressure ports are positioned in the wall along the combustor which has the diameter of $1.0 \mathrm{~mm}$, towards flow direction to measure the combustor surface static pressures. Two types of pressures, such as static and stagnation are assessed near the outlet of the combustor by supersonic static and pitot pressure probes to measure the flow features which is mainly based on the cavities. The experiments are performed at least trice to ensure the repeatability. The uncertainties of the measured pressure values are less than $3 \%$. A mechanism with traverse arrangement is utilized to shift the probes along exit plane of the combustor perpendicular to the direction of the flow.

\section{RESULTS AND DISCUSSIONS}

\section{A. Wall Static Pressure Distribution}

The wall static pressure acquired from the various cavity configuration of the supersonic combustor towards the flow direction is represented in figure 3 .

In the figure $3 a, 3 b$ and $3 c$, the wall static of various rear walled angled cavity models are compared with combustor axial distance. The distance from the inlet of the combustor to the pressure port is termed as ' $x$ ' whereas the total length of the combustor as 'Lc'. In all the figures, the rectangular cavity $(90,90)$ is considered to be the baseline cavity which is compared with other rear wall angled cavity configurations. Increase in static pressure at the proximate leading edge (i.e. at $\mathrm{x} / \mathrm{Lc}=0.29$ ) of the rectangular cavity is owed to separated shear layer characteristics inherited in the flow that promotes stronger shock waves, leading to compressive zone

A flapping motion is developed which leads to the formation of a recirculation zone at the cavity inner zone at the trailing edge where the shear layer reattaches. The flow becomes unstable in the adjacent areas of the cavity region which further induces flow mixing. A stable flow field is required near the vicinity of flameholding device. When the secondary angle of the cavity is reduced to $45^{\circ}$, the flow near cavity leading edge is inferred to be even compressive in nature due to the shear layer reattachment occurring at $\mathrm{x} / \mathrm{Lc}=$ 0.68 . Further reduction in secondary rear angle $(\theta 2)$ reduces the static pressure distribution within the domain of the cavity and increases at the rear wall of the cavity i.e., at the region were shear layer reattaches. The further reduction in secondary cavity wall angle decreases the static pressure within the cavity region which clearly depicts a stable flow field. Static pressure is detected to have a gradual increment for the secondary cavity wall angles $(\theta 2)$ of $15^{\circ}$ and $30^{\circ}$ than $45^{\circ}$ and this can be depicted owing to the trait of reattachment of shear layers which spans over the rear wall effective length of the cavity (Fig. 3a). On account of the circular shaped test cross-section, experimental flow visualisation techniques is difficult to be implemented in this study. The schlieren images of the 2D rear wall angle cavities reported by Vikramathiya and Kurian [13] unveil that flow above the cavity at the rear wall angle of $30^{\circ}, 15^{\circ}$ depicts a stable flow field. Furthermore, higher amplitude of oscillations within the cavity region at the absence of upstream flow, a travelling wave was observed from the unsteady pressure measurement for rear wall angles of $30^{\circ}$ and $15^{\circ}$ when compared to the cavity rear wall angle of $45^{\circ}$. Above 2D experimental flow visualisation work reference [13] justifies that stable flow is ensured at the cavity region for rear wall angles $(\theta 2)$ of $30^{\circ}$ and $15^{\circ}$, that is desirable for scramjet combustors flame holding and stabilisation. 


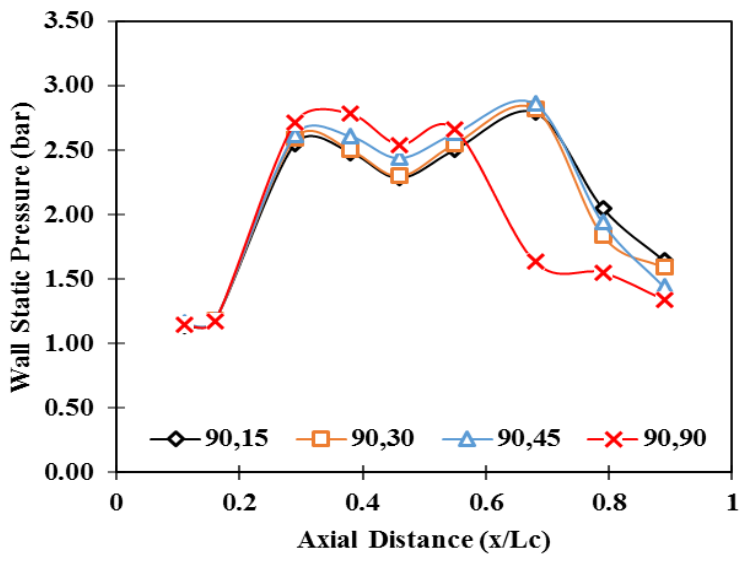

(a)

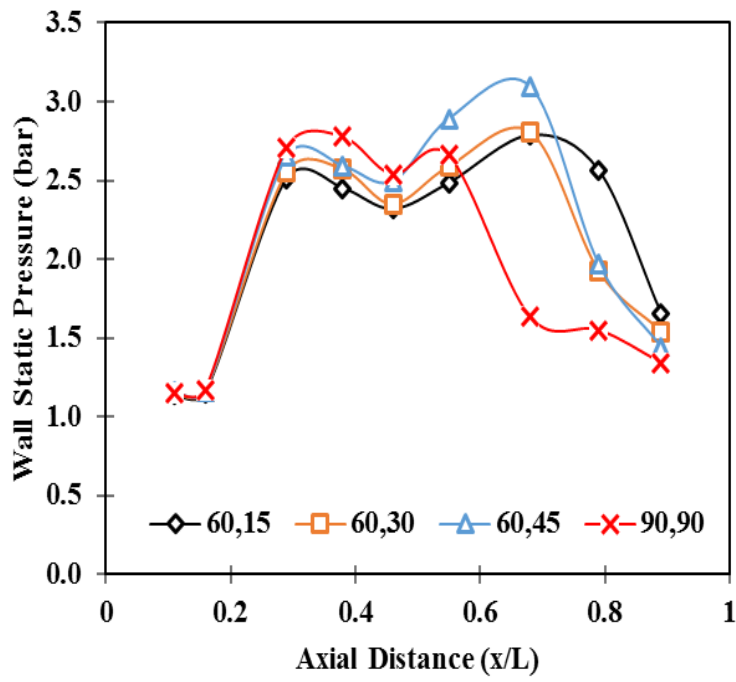

(b)

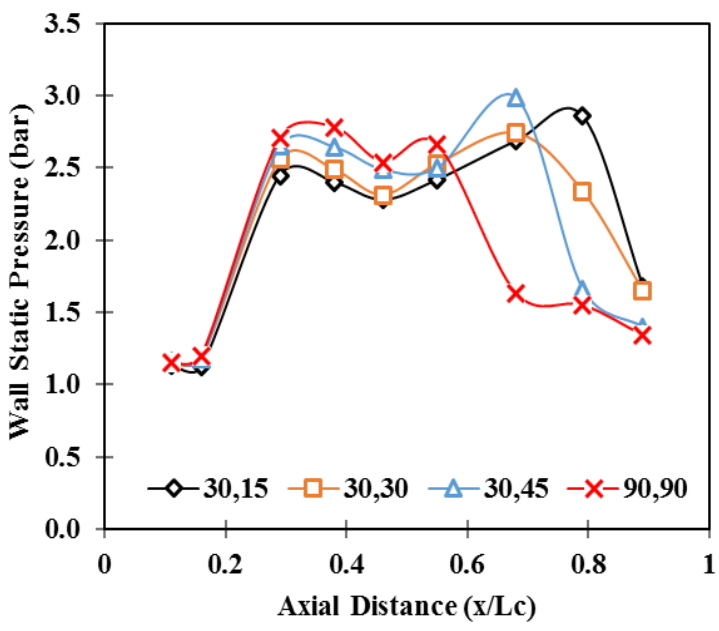

(c)

Fig. 3. Wall static pressure for cavity primary angles of (a) 90 degree, (b) 60 degree and (c) 30 degree

An analogous trend is noticed at cavity rear wall angle $(\theta 1)$ of $60^{\circ}$ (Fig. 3b). Furthermore, wall static pressure magnitude is observed to be higher than the rear ramp angle of $90^{\circ}$. As illustrated in Fig. 3c, the static pressure of wall in the cavity domain increases on further decline in cavity rear wall angle $(\theta 1)$ to $30^{\circ}$. Above results ratifies that the effective length of the cavity increases with decrease in rear wall angles. A compressive zone is created within the cavity domain as the shear layer reattaches at the cavity rear wall of the cavity which stretches completely above the secondary rear wall of the cavity. The shock wave generated owing from the expanded effective length of the rear wall predominantly obstructs the mainstream flow which resulted in an increment in the cavity drag.

\section{B. Momentum Flux Distribution}

The extent of bulk mixing characteristics of the flow by the cavity can be found out by evaluating the momentum flux distribution at the exit plane of the supersonic combustor. The momentum flux values for various specific distances from the centre of the flow regime are assessed using the following equation;

$$
\mu=p\left(1+\gamma M^{2}\right)
$$

where ' $p$ ' refers to static pressure measurement and the value of the Mach number (M) being calculated using Rayleigh-Pitot tube formula using the measured quantities of static and stagnation pressures.

The measurements are taken out at regular inline radial locations at the supersonic combustor exit from the centre along the wall. Figure 4. illustrates the momentum flux profile at different rear ramp angled cavities for the chosen regular exit radial locations of the combustor. In the Figure $4 \mathrm{a}, 4 \mathrm{~b}$ and $4 \mathrm{c}$, the value of the radial distance from the axis ( $\mathrm{r}$ ) normalized with respect to radius (R) of supersonic combustor is taken in the radial direction and represented as $\mathrm{r} / \mathrm{R}$. The momentum flux values are experimentally measured under similar operating conditions which are plotted for declining cavity rear ramp angles and contrasted with a rectangular cavity $(90,90)$. Momentum flux value reaches the highest value at the centre portion of the combustor and reduces towards the wall and is outlined owing to the higher operating centre pressure than at the wall. The mixing uniformity characteristics of the flow within the combustor can be depicted from the momentum flux profile at the exit of the combustor. Non-uniform momentum flux profile is observed for a rectangular cavity and is assessed due to the unstable nature of the flow in the cavity domain. Reduction in rear wall angle $(\theta 2)$ from $90^{\circ}$ to $15^{\circ}$ leads to a marginal increase in momentum flux value which is mainly observed near the wall of the combustor. An indication of $6 \%$ variation in momentum flux profile showing a marginal increase in uniformity of mixing is observed when declining the primary rear cavity wall angle from $90^{\circ}$ to $60^{\circ}$ (Figure 4b). Further declining the primary rear wall angle $(\theta 1)$ shows a uniform mixing profile (Figure $4 \mathrm{c}$ ) within the cavity regardless of the reduction in secondary rear wall angles when related with rectangular cavity configurations. 


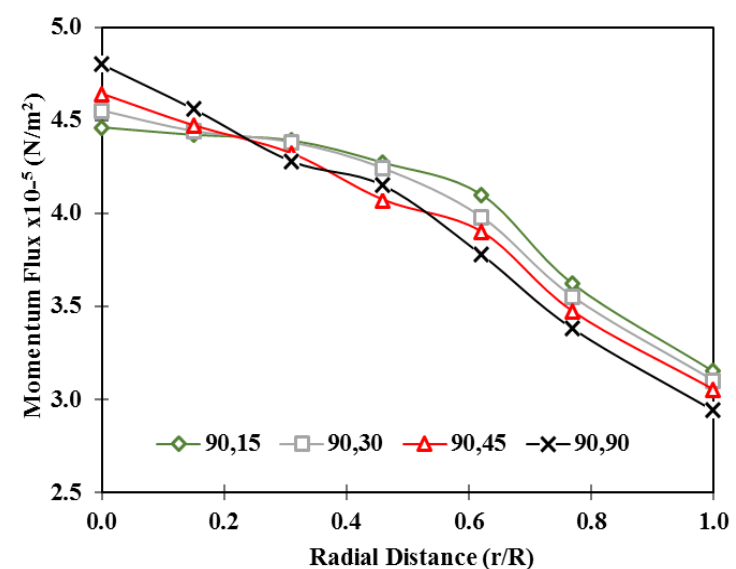

(a)

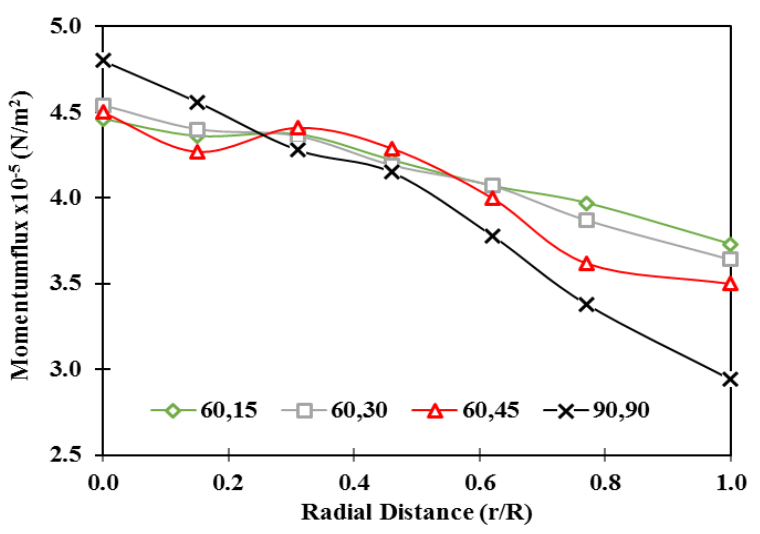

(b)

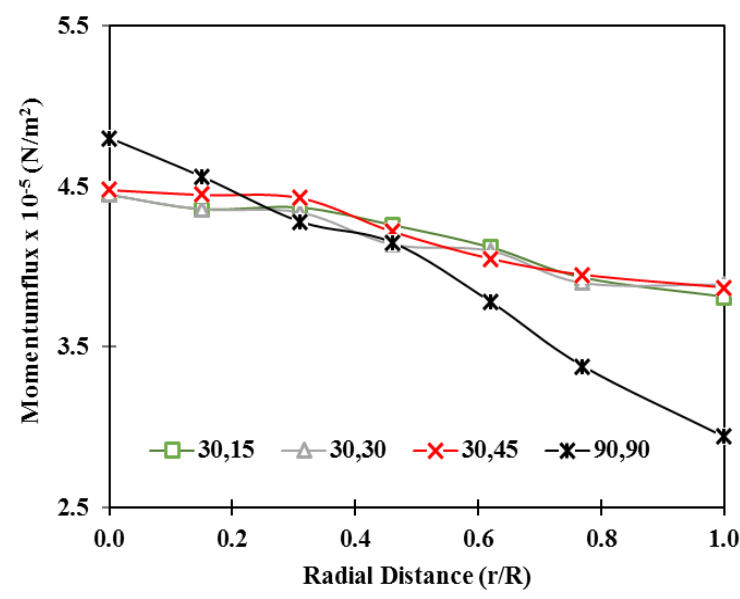

(c)

Fig. 4.Momentum flux distribution profile for the cavity primary angle of (a) 90 degree, (b) 60 degree and (c) 30 degree

\section{Stagnation Pressure Loss}

Stagnation pressure drops as a result of the improvement in mixing provided by the wall angled cavities which consecutively rise the cavity drag. The value of the stagnation pressure drop along the flow in the combustor is determined from the variations in stagnation pressure at the inlet over axial distance of the combustor, which is normalized by inlet stagnation pressure. The variations in stagnation pressure loss over the several tested cavity configurations are depicted in Figure 5. The loss in stagnation pressure for the rectangular cavity is found to be $21.54 \%$. The pressure loss is by virtue of unstable flow above the cavity domain which interferes with the core flow and forms a compressive zone. From the figure, it is observed that the reduction in both primary, as well as secondary rear wall angles, decrease the pressure loss which ascertains the establishment of stabilized flow field at the cavity region.

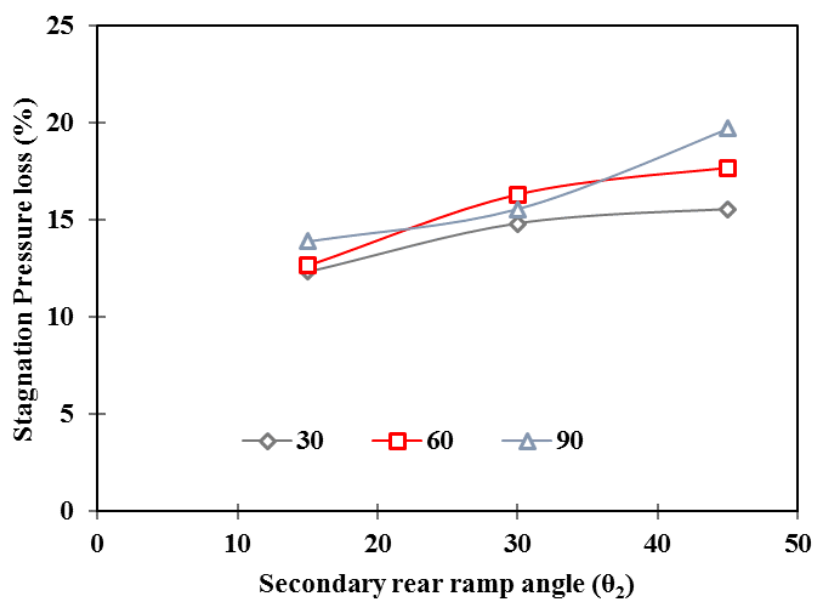

Fig. 5.Stagnation pressure loss for cavity varying rear ramp angles

\section{CONCLUSION}

The non-reacting experiments are performed to study the behavior of aft wall angled cavities in a Mach 1.5 flow field using a blow down flow facility. Open cavities of axisymmetric geometric with varying aft ramp angles are investigated under the same operating conditions. The following conclusions are denoted from the study: the static pressure is lower along the base of the cavity and increases at the aft ramp of the cavity due to recompression of shear layers. This static pressure profiles of the cavity flow appears to be lower with reduction in the aft ramp angle of the cavity shows a stable flow field in the cavity regime compared to the rectangular counterpart. The momentum flux profile refers to the mixing enhancement achieved primarily by decreasing the cavity's rear wall angles. Hence, the rear wall cavity angles and flow stability characteristics in the cavity regime play a vital role in flame holding characteristics in scramjet engine combustors.

\section{ACKNOWLEDGMENT}

Under Grant No: SR/FTP/ETA-55, this work is supported by the Department of Science and Technology.

\section{REFERENCES}

1. Yu KH, Wilson KJ, Schadow KC. Effect of Flame-Holding Cavities on Supersonic-Combustion Performance. Journal of Propulsion and Power, 2001;17:1287-1295. doi:10.2514/2.5877.

2. M. C. Mohamed Ali, Kurian J. Performance of Aft-Ramp Cavities for Flame Stabilization in Supersonic Flows, Journal of Propulsion and Power, 2008, Vol. 24, No. 3, DOI: 10.2514/1.34751 
3. Maurya et al, "Effect of aft wall offset and ramp on pressure oscillation from confined supersonic flow over cavity", Experimental Thermal and Fluid-Science, 2015, 68, 559-573., doi:10.1016/j.expthermflusci.2015.06.014.

4. Sudhir L Gai, Harald Kleine and Andrew J Neely, "Supersonic flow over a shallow open rectangular cavity “, Journal of Aircraft, 2015, Vol.52, No.2, pp:609-616. doi.:10.2514/1.C032781.

5. Rajarshi Das, Heuy-Dong Kim and Job Kurien, "Experimental study of supersonic entrainment using a cavity", AIAA Journal of Propulsion and Power, 2014, Vol.30, No.5, pp.1143-1151.

6. Wei Huang, Zhen-guo Wang, Li Yan and Wei-dong Liu, "Numerical validation and parametric investigation on the cold flow field of a typical cavity-based scramjet combustor", Elsevier Journal, Acta Astronautica, 2012, Vol.80, pp.132-140.

7. Ming-Bo Sun, Hui Geng, Jian-Han Liang, and Zhen-Guo Wang. "Flame Characteristics in Supersonic Combustor with Hydrogen Injection Upstream of Cavity Flameholder", Journal of Propulsion and Power, 2008, Vol. 24, No. 4 (2008), pp. 688-696.doi: $10.2514 / 1.34970$.

8. Yih Nen Jeng and Uon Jan Payne, " Numerical study of Supersonic open cavity flow and pressure oscillation control ", AIAA Journal of Aircraft, Vol.32, No.2, March-April 1995, pp.363-369

9. Sang Hun kang et al, "Scramjet Engine Combustor Tests in a supersonic Wind Tunnel with a Vitiated Air Heater" , 46th AIAA/ASME/SAE/ASEE Joint Propulsion Conference \& Exhibit, July 2010, AIAA 2010-7123.

10. Wei Huang et al, "Effect of geometric parameters on the drag of the cavity flameholder based on the variance analysis method", Elsevier

11. W. Huang et al., "Flow-Field Analysis of a Typical Hydrogen-Fueled Dual-Mode Scramjet Combustor," Journal of Aerospace Engineering, vol. 25, no. 3, pp. 336-346, 2012.

12. Jeyakumar S, Shan M Assis, K Jayaraman, Effect of Axisymmetric Aft Wall Angle Cavity in Supersonic Flow Field, International Journal of Turbo \& Jet-Engines, DOI: 10.1515/tij-2016-0027, June 2016.

13. Maurya PK, C. R, R.R. VK, Vaidyanathan A. Effect of aft wall offset and ramp on pressure oscillation from confined supersonic flow over cavity. Exp Therm Fluid Sci 2015;68:559-73. doi:10.1016/j.expthermflusci.2015.06.014.

14. Vikramaditya NS, Kurian J. Pressure Oscillations from Cavities with Ramp. AIAA J 2009;47:2974-84. doi:10.2514/1.43068.

15. Jeyakumar S, Shan M Assis, K Jayaraman, "Experimental Study on the Characteristics of Axisymmetric Cavity Actuated Supersonic Flow", Proc IMechE Part G: Journal of Aerospace Engineering, 2017 1-8, IMechE August 2016, DOI: 10.1177/0954410016667149

\section{AUTHORS PROFILE}

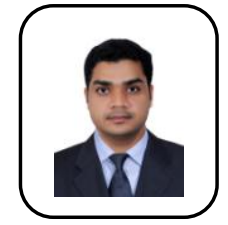

Shan M Assis is a post graduate in Mechanical engineering and currently a PhD Research Scholar at Kalasalingam Academy of Research and Education, Tamil Nadu, India. His research interest areas are on Supersonic Combustion, Refrigeration \& Heat Transfer applications and Flow simulation studies.

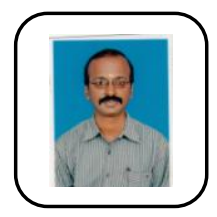

Dr. S. Jeyakumar working as Professor in Aeronautical Engineering, Kalasalingam Academy of Research and Education. The author has published papers in the areas of high-speed flow mixing and combustion, cavity flow, dual combustion ramjet engine.

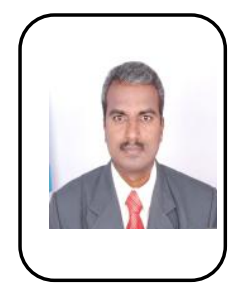

Prof. Dr. K. Jayaraman is presently working as Principal Scientist at Department of Aerospace Engineering, IIT Madras, Chennai He was awarded for Sandwich Postdoc Fellowship from Science Technology and Service, Embassy of France, New Delhi, India. He research areas are solid propellants, renewable energy technology; the pyrolysis, combustion and gasification studies of several carbonaceous materials, 